\title{
Analisa Pendapatan, Nilai Tambah, dan Strategi Pengembangan Usaha di Sentra Kerajinan Kulit Selosari Kabupaten Magetan, Jawa Timur
}

\section{Analysis of Income, Added Value, and Business Developing Strategy at Selosari Leathercraft Centre of Magetan District, East Java}

\author{
Y. P. Perwitasari* dan Soetriono \\ Program Studi Agribisnis, Fakultas Pertanian, Universitas Jember - Indonesia \\ *Corresponding E-mail: putriyofita@gmail.com \\ (Diterima: 15 Januari 2020; Disetujui: 22 Maret 2020)
}

\begin{abstract}
ABSTRAK
Penelitian dilakukan pada sentra kerajinan kulit di kelurahan Selosari Magetan, Jawa Timur untuk mengetahui tiga hal, yaitu (1) Pendapatan dan efisiensi penggunaan biaya produksi industri alas kaki, (2) Nilai tambah produk, dan (3) strategi pengembangan industri. Data dikumpulkan dari 10 pelaku usaha dan 5 tenaga ahli yang mewakili instansi dan pihak terkait. Data terkumpul diolah menggunakan tiga kategori; analisa R/C ratio, analisis nilai tambah Hayami, dan AHP (Analytical Hierarcy Process). Hasil penelitian menunjukkan (1) rata-rata $\mathrm{R} / \mathrm{C}$ ratio 1,23; (2) produk alas kaki dari kulit memiliki nilai tambah sebagai berikut; sepatu wanita Rp 30.707,71; sepatu laki-laki Rp 30.129,60; sandal laki-laki Rp 25.281,98; dan sandal wanita $\operatorname{Rp} 23.475,61$; dan (3) strategi yang relatif tepat adalah pada kriteria pengembangan produksi dengan bobot 0,490 .

Kata kunci: industri kerajinan kulit, pendapatan, nilai tambah, strategi pengembangan

\section{ABSTRACT}

This study was conducted at the leathercraft center in Selosari Village, Magetan district, East Java, to determine three things. (1) Income and the efficient use of footwear industry production costs, (2) product value-added, and (3) industrial development strategy. Data were collected from 10 business actors and five experts representing agencies and related parties. The collected data were processed using three categories: $R / C$ ratio analysis, value-added analysis, and AHP (Analytical Hierarchy Process). The result of the study showed: (1) the income of the leather footwear handicraft industry was profitable, with an average $R / C$ ratio of 1.23; (2) leather footwear handicraft products had added value with the added value of women's shoes Rp 30,707.71; men's shoes Rp. 30,129.60; men's sandals Rp. 25,281.98; women's sandals Rp. 23,475.61; and (3) the development strategy, which is considered relatively appropriate, is the production criteria with a weight of 0.490 .
\end{abstract}

Keywords: leather footwear craft, income, added value, AHP

\section{PENDAHULUAN}

Kulit merupakan hasil samping dari peternakan sapi potong yang dapat diolah menjadi kulit perkamen dan kulit samak. Kulit samak dapat digunakan untuk bahan baku kerajinan kulit seperti alas kaki (sepatu dan sandal). Industri kerajinan kulit memiliki potensi untuk dikembangkan di Indonesia, sebab masih sedikitnya industri besar yang mengelola secara intensif (Setyaningsih, 2017).

Menurut Erawati dan Kirwani (2014) industri penyamakan kulit sebagai industri hulu dan industri kerajinan kulit sebagai industri hilir. Keterkaitan antar industri diharapkan dapat mengembangkan potensi daerah sekitar. Menurut Hadinata (2014) Jawa Timur merupakan salah satu provinsi yang mengandalkan UMKM dan Koperasi dalam 
Tabel 1. Industri kulit di Kabupaten Magetan pada tahun 2016-2018

\begin{tabular}{lccc}
\hline Jenis Industri & 2015 & 2016 & 2017 \\
\hline Penyamakan Kulit & 139 & 139 & 186 \\
Alas Kaki dari Kulit & 220 & 220 & 260 \\
Kerajinan Tatah Ukir Kulit & TD & 1 & 1 \\
Kerajinan Tas dari Kulit & TD & TD & 20 \\
Kerajinan Dompet & TD & TD & 20 \\
\hline
\end{tabular}

Sumber: BPS Kabupaten Magetan (2016, 2017, dan 2018)

memajukan perekonomian daerah. Salah satu kabupaten yang memiliki industri hulu dan industri hilir di Provinsi Jawa Timur adalah Kabupaten Magetan.

Industri alas kaki dari kulit mengalami pertumbuhan sebesar $18,18 \%$ pada tahun 2017 sedangkan pada tahun 2016 tidak terdapat pertumbuhan, sehingga industri alas kaki dari kulit ini perlu mendapatkan perhatian untuk bisa berkembang (Tabel 1).

Industri alas kaki dari kulit di Kabupaten Magetan tersentra di Kelurahan Selosari, dimana sentra ini memproduksi sandal dan sepatu. Pengerajin membatasi produksi alas kaki setiap produksinya karena disesuaikan dengan permintaan pasar. Hal ini tentu berpengaruh terhadap biaya yang digunakan, mengingat industri di Kabupaten Magetan merupakan industri skala Mikro hinggal kecil.

Hasil industri penyamakan kulit belum terserap $100 \%$ oleh kerajinan kulit, sehingga adanya kegiatan ekspor kulit samak. Padahal harga ekspor dan harga lokal hampir sama, dimana untuk pasar ekspor RP 25.000/feet (BPS, 2020) dan di pasar lokal bisa mencapai 20.000/feet, sehingga menarik untuk dilihat pada nilai tambah produk. Produk alas kaki dari Magetan mengalami branding ulang sehingga kurang terkenal dan kurang bisa bersaing.

Penelitian ini dilakukan untuk menjawab fenomena dari latar belakang tersebut sehingga penelitian ini memiliki tujuan: 1) mengetahui pendapatan dan efisiensi biaya produksi kerajinan alas kaki, 2) mengetahui nilai tambah dari produk kerajinan alas kaki, dan 3) merumuskan strategi pengembangan industri kerajinan alas kaki dari kulit di sentra Kabupaten Magetan.

\section{METODE}

\section{Tempat dan Waktu Penelitian}

Penelitian dilaksanakan di sentra Kerajinan Kulit J1. Sawo, Kelurahan Selosari Kecamatan Magetan Kabupaten Magetan (UD. Praktis, Figha Shoes, UD. Sempurna, Toko Sepatu Menink, Kartika Exclusive, PS. Ireng, Soldate Leather, HIDAYAH, Rif'at, dan Nesha Shoes), Dinas Perindustrian dan Perdagangan Kabupaten Magetan. Penelitian ini dilakukan pada bulan Mei-November 2019.

\section{Metode Penelitian}

Penentuan daerah penelitian dilakukan dengan menggunakan metode purposive method dengan pertimbangan Kelurahan Selosari merupakan sentra kerajinan alas kaki dari kulit. Metode penentuan responden menggunakan metode total sampling, dimana menggunakan 10 industri kerajinan alas kaki yang masih aktif untuk menjawab rumusan masalah 1 dan 2, sedangkan untuk rumusan masalah 3 menggunakan expert (Tabel 2).

Data yang digunakan dalam penelitian merupakan data primer, yaitu data yang diperoleh berdasarkan observasi atau pengamatan secara langsung di lapangan dan wawancara terhadap responden dengan menggunakan Kuesioner, serta data sekunder yang berasal dari BPS, Dinas Perindutrian dan Perdagangan Kabupaten Magetan.

Rumusan masalah pertama pendapatan 
Tabel 2. Jumlah Expert

\begin{tabular}{clc}
\hline No & Expert & Jumlah (Orang) \\
\hline 1 & Dinas Perindustrian dan Perdagangan Kabupaten Magetan & 1 \\
2 & Penyuluh & 1 \\
3 & Ketua Sentra Industri & 1 \\
4 & Pengusaha industri & 1 \\
\hline & Jumlah & 5 \\
\hline
\end{tabular}

dan efisiensi penggunaan biaya produksi industri kerajinan alas kaki dianalisis menggunakan analisis pendapatan dan $\mathrm{R} / \mathrm{C}$ ratio. Analisis ini untuk mengetahui biaya pada proses produksi, menurut Hariyati (2007) yaitu:

\section{Total Biaya Tetap}

Biaya tetap merupakan biaya yang digunakan untuk faktor produksi tetap. Biaya ini termasuk dalam jangka pendek, dimana faktor produksi tetap. Jumlah biaya tetap tidak bergantung pada jumlah produk yang dihasilkan.

Investasi pada biaya tetap akan menimbulkan biaya penyusutan, dimana penyusutan dalam penelitian ini menggunakan metode garis lurus. Berikut merupakan metode penyusutan garis lurus yang digunakan berdasarkan Waluyo (2008):

Biaya penyusutan $=$ Tarif penyusutan $\mathrm{x}$ Dasar perhitungan penyusutan

\section{Total Biaya Variabel}

Biaya variabel dapat berupa uang tunai, barang atau nilai jasa, biaya ini ditentukan oleh fungsi produksi atau produk total. Secara keseluruhan dapat disimpulkan bahwa semakin banyak maka akan semakin besar pula biaya variabel yang diperlukan.

\section{Biaya Total}

Biaya total adalah penjumlahan biaya tetap dan biaya variabel. Rumus biaya total menurut Soetriono et al. (2017):

$$
\mathrm{TC}=\mathrm{TFC}+\mathrm{TVC}
$$

Keterangan:

TC : Total biaya industri kerajinan alas kaki

$$
\text { dari kulit ( } \mathrm{Rp})
$$

TFC: Total biaya tetap industri kerajinan alas kaki dari kulit (Rp)

TVC: Total biaya variabel industri kerajinan alas kaki dari kulit (Rp)

Penerimaan dapat dihitung dengan mengalikan jumlah produk dalam satu kali proses produksi dengan harga per satuan produk, dimana dapat ditulis dengan rumus:

$$
\mathrm{TR}=\mathrm{P} \times \mathrm{Q}
$$

Keterangan:

TR : Total Penerimaan industri kerajinan alas kaki dari kulit (Rp/Proses Produksi)

$\mathrm{P}$ : Harga per produk $(\mathrm{Rp})$

Q : Jumlah Produksi alas kaki (Produk/ Proses Produksi)

Pendapatan dituliskan dengan rumus:

$$
\Pi=\text { TR-TC }
$$

Keterangan:

TR : Total Penerimaan ( $\mathrm{Rp})$

TC : Total Biaya (Rp)

Menurut Soekartawi(1995) perhitungan efisiensi penggunaan biaya produksi adalah :

$$
\mathrm{a}=\mathrm{R} / \mathrm{C}
$$

Keterangan:

$\mathrm{R}:$ Penerimaan $(\mathrm{Rp})$

C : Biaya (Rp)

Kriteria:

1. Jika $\mathrm{R} / \mathrm{C}$ ratio $>1$, maka penggunaan biaya produksi usaha tersebut efisien.

2. Jika $\mathrm{R} / \mathrm{C}$ ratio $<1$, maka penggunaan biaya produksi usaha tersebut tidak efisien. 
Tabel 3. Prosedur Perhitungan Nilai Tambah Insdustri Kerajinan Kulit di Kabupaten Magetan.

\begin{tabular}{cll}
\hline No & Variabel & Nilai \\
\hline \multirow{2}{*}{1} & Output, Input dan Harga & \\
2 & Output (Pasang/Produksi) & $(1)$ \\
3 & Bahan baku (Feet/Produksi) & $(2)$ \\
4 & Fenaga kerja langsung (Jam/Produksi) & $(3)$ \\
5 & Koefisien tenaga kerja & $(4)=(1) /(2)$ \\
6 & Harga Output (RP/pasang) & $(5)=(3) /(2)$ \\
7 & Upah Tenaga kerja langsung(RP/Jam) & $(6)$ \\
& Penerimaan dan Keuntungan & $(7)$ \\
\hline 8 & Harga bahan baku (Rp/) & $(8)$ \\
9 & Harga input lain (Rp/ Pasang) & $(9)$ \\
10 & Nilai produk (Rp/pasang) & $(10)=(4) \times(6)$ \\
11 & a. Nilai tambah (Rp/pasang) & $(11 \mathrm{a})=(10)-(8)-(9)$ \\
& b. Rasio nilai tambah (\%) & $(11 \mathrm{~b})=(11 \mathrm{a}) /(10) \times 100$ \\
12. & a. Pendapatan tenaga kerja (Rp/pasang) & $(12 \mathrm{a})=(5) \times(7)$ \\
& b. Rasio tenaga kerja langsung (\%) & $(12 \mathrm{~b})=(12 \mathrm{a}) /(11 \mathrm{a}) \times 100$ \\
13 & a. Keuntungan (Rp/Pasang) & $(13 \mathrm{a})=(11 \mathrm{a})-(12 \mathrm{a})$ \\
& b. Rasio Keuntungan (\%) & $(13 \mathrm{~b})=(13 \mathrm{a}) /(10) \times 100$ \\
\hline
\end{tabular}

3. Jika $\mathrm{R} / \mathrm{C}$ ratio $=1$, maka penggunaan biaya produksi usaha tersebut impas.

Rumusan masalah kedua yaitu nilai tambah dari produk alas kaki dari kulit dapat dihitung menggunakan metode Hayami. Menurut Sudiyono dalam Marimin dan Maghfiroh (2010), analisis nilai tambah oleh Hayami memiliki kelebihan, yaitu:

1. Dapat diketahui besarnya nilai tambah.

2. Dapat diketahui balas jasa terhadap pemiliki faktor produksi.

3. Dapat diterapkan diluar subsistem pengolahan.

Perhitungan nilai tambah seperti terlihat pada Tabel 3. Nilai tambah dapat diketahui dengan:

$$
\mathrm{VA}=\mathrm{NP}-\mathrm{IC}
$$

Kriteria pengambilan keputusan:

1. Apabila nilai tambah $>0$, maka industri tersebut dapat memberikan nilai tambah.

2. Apabila nilai tambah $<0$, maka industri tersebut tidak dapat memberikan nilai tambah.

Rumusan masalah ketiga yaitu strategi pengembangan industri kerajinan alas kaki dari kulit, dalam penelitian ini perumusan strategi pengembangan dilakukan dengan menggunakan Analysis Hierarcy Process (AHP). Menurut Mulyono (1996) AHP merupakan suatu teori umum tentang pengukuran, digunakan untuk menemukan skala rasio baik dari perbandingan pasangan maupun kontinyu.

Menurut Saaty (1991) pada penetapan prioritas elemen-elemen dalam suatu pengambilan keputusan adalah dengan membuat pembanding berpasangan, yaitu: elemen-elemen dibandingkan berpasangan terhadap kriteria yang ditentukan. Elemenelemen tersebut ditentukan dari hasil observasi dan tinjauan pustaka. Kerangka hirarki keputusan dapat dilihat pada Gambar 1. 


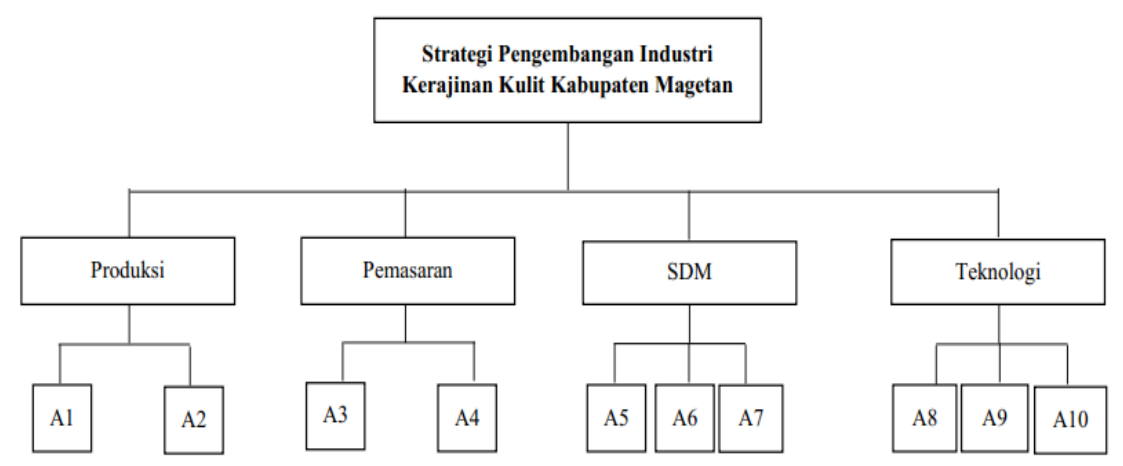

Gambar 1. Kerangka hirarki proses pengambilan keputusan (Sumber: Derajat, 2014)

Keterangan:

A1= Melakukan Pelatihan Manajemen dan Inovasi Produk

A2 $=$ Mempertahankan Kualitas Produk

A3 = Memanfaatkan Promosi Pemerintah Daerah

A4 $=$ Penyediaan informasi pasar (katalog)

A5 = Pelatihan untuk meningkatkan ketrampilan teknis

A6 $=$ Mengadakan Balai Latihan Kerja khusus kerajinan kulit

A7 $=$ Meningkatkan pengetahuan pengolahan limbah

A8 $=$ Memberikan bantuan teknologi dengan harga terjangkau

A9 $=$ Pengembangan industri pengolahan limbah

A10 $=$ Pengembangan industri mesin pengolah kulit

\section{HASIL DAN PEMBAHASAN}

\section{Analisis Pendapatan Industri Kerajinan Alas Kaki dari Kulit}

Kabupaten Magetan merupakan daerah yang sedang berkembang, dimana banyak unit usaha industri dengan skala mikro-kecil. Produk kerajinan alas kaki dari kulit menjadi salah satu industri yang cukup menguntungkan dengan pendapatan yang besar. Pendapatan dapat diperoleh dengan mengurangkan penerimaan (TR) dengan biaya total (TC).

Penerimaan total dari industri Kerajinan alas kaki dari kulit setiap produksi sebesar Rp. 648.250, dengan penerimaan tertinggi pada industri Figha Shoes yaitu sebesar Rp. 1.556.250 (Tabel 4). Hal ini disebabkan karena Figha Shoes memiliki rata-rata produksi tertinggi, dengan harga yang tinggi. Data penerimaan ini kemudian dapat digunakan untuk menghitung pendapatan yang diperoleh dari setiap kali produksi. Pendapatan merupakan selisih antara penerimaan dengna biaya total yang digunakan.
Pendapatan yang diterima pengerajin di sentra kerajinan alas kaki dari kulit Kabupaten Magetan setiap kali produksi ratarata sebesar Rp. 175.975,59. Artinya pengrajin mendapatkan keuntungan setiap kali proses produksi. Pendapatan terbesar diperoleh pada industri Figha Shoes yaitu sebesar Rp. $515.532,75$, sedangkan pendapatan terendah pada Hidayah yaitu Rp. 22.461,09 (Tabel 5). Penerimaan tinggi ketika harga lebih tinggi dan jumlah produk lebih banyak, sedangkan untuk penggunaan biaya semakin rendah, sehingga memperoleh pendapatan yang tinggi. Hal ini sesuai dengan penelitian Wibowo (2009) yang menyatakan bahwa usaha kerajinan sepatu menguntungkan.

\section{Efisiensi Penggunaan Biaya Produksi}

Analisis yang digunakan untuk mengetahui efisiensi penggunaan biaya produksi industri kerajinan alas kaki dari kulit di sentra kerajinan Kabupaten Magetan adalah menggunakan analisis $\mathrm{R} / \mathrm{C}$ ratio. Analisis $\mathrm{R} / \mathrm{C}$ ratio digunakan dengan membandingkan antara total penerimaan dengan total biaya 
Tabel 4. Rata-rata jumlah produksi dan penerimaan total industri kerajinan alas kaki dari kulit Kabupaten Magetan

\begin{tabular}{llccc}
\hline No Industri & $\begin{array}{c}\text { Jumlah produksi } \\
\text { (Pasang) }\end{array}$ & Harga Jual (Rp) & Penerimaan Total (Rp) \\
\hline 1 & UD. Praktis & 7 & 156.250 & 1.187 .500 \\
2 & Figha Shoes & 10 & 150.000 & 1.556 .250 \\
3 & UD. Sempurna & 8 & 150.000 & 1.250 .000 \\
4 & Toko Sepatu Menink & 3 & 137.500 & 425.000 \\
5 & Kartika Exclussive & 4 & 116.250 & 477.500 \\
6 & PS. Ireng & 3 & 117.500 & 362.500 \\
7 & Soldate Leather & 2 & 177.500 & 361.250 \\
8 & Hidayah & 2 & 105.000 & 216.250 \\
9 & Rif'at & 3 & 125.000 & 387.500 \\
10 & Nesha Shoes & 2 & 121.250 & 258.750 \\
\hline & Jumlah & 44 & 1.356 .500 & 6.482 .500 \\
\hline & Rata-rata & 4,4 & 135.650 & 648.250 \\
\hline
\end{tabular}

Sumber: Data Primer diolah tahun 2019

yang dikeluarkan dalam suatu usaha.

Nilai efisiensi biaya rata-rata dari produk kerajinan alas kaki dari kulit memiliki $\mathrm{R} / \mathrm{C}$ ratio 1,28 , dimana artinya $\mathrm{R} / \mathrm{C}$ ratio lebih dari 1 maka penggunaan biaya pada usaha tersebut sudah efisien. Nilai $\mathrm{R} / \mathrm{C}$ ratio 1,28 menunjukkan bahwa setiap pengeluaran biaya produksi sebesar 1 rupiah akan memperoleh penerimaan sebesar Rp. 1,28, sehingga mendapatkan keuntungan sebesar 0,28 rupiah. Nilai $\mathrm{R} / \mathrm{C}$ ratio tertinggi diperoleh pada industri Soldate Leather dengan nilai sebesar 1,53 , sedangkan untuk nilai $\mathrm{R} / \mathrm{C}$ ratio terendah diperoleh pada industri Hidayah dengan nilai sebesar 1,09 (Tabel 5).

Hasil analisis pendapatan dan efisiensi penggunaan biaya produksi memiliki hasil yang berbeda pada nilai tertinggi. Hal ini disebabkan oleh perbedaan penggunaan tenaga kerja, dimana pada industri Figha Shoes menggunakan sistem pembayaran perbulan, sedangkan pada industri Soldate Leather sistem pembayaran perbulan pada bagian desain dan finishing, serta sistem borongan pada bagian upper dan assembling, namun tidak menggunakan tenaga kerja untuk bagian tolo, karena pemasarannya menggunakan sistem online. Hal ini tentu mengurangi penggunaan biaya produksi sebanyak 3,72\%$14,42 \%$, sesuai dengan penelitian yang menyatakan bahwa usaha kerajinan sepatu sudah efisien (Wibowo, 2009).

\section{Analisis Nilai Tambah}

Pengerajin alas kaki dari kulit yang melakukan produksi dengan baik dapat meningkatkan nilai tambah dari hasil kulit samak yang telah diproses. Produk yang dihasilkan oleh industri kerajinan alas kaki di sentra kerajinan alas kaki Kabupaten Magetan cukup banyak, namun pada penelitian ini hanya berfokus produk sepatu pria, sepatu wanita, sandal pria, dan sandal wanita.

Setiap pengolahan satu feet bahan baku kulit samak akan menghasilkan 0,50 pasang sepatu wanita dan 0,40 pasang sepatu pria. Rata-rata harga sepatu wanita Rp. 145.500 dan sepatu pria Rp. 180.500 per pasang. Biaya yang digunakan dalam proses produksi adalah biaya bahan baku dan biaya bahan input lain. Harga satu feet bahan baku kulit box Rp. 15.950,- sedangkan harga input lain untuk mengolah 1 feet bahan baku kulit box produk sepatu wanita adalah sebesar Rp. 26.092,29 dan sepatu pria sebesar Rp. 15.753,66 (Tabel 
Tabel 5. Rata-rata pendapatan industri kerajinan alas kaki dari kulit

\begin{tabular}{llrrrc}
\hline No Industri & $\begin{array}{c}\text { Penerimaan } \\
(\mathrm{Rp})\end{array}$ & Biaya (Rp) & $\begin{array}{c}\text { Pendapatan } \\
(\mathrm{Rp})\end{array}$ & R/C Ratio \\
\hline 1 & UD.Praktis & 1.187 .500 & $819.646,80$ & $367.853,30$ & 1,41 \\
2 & Figha Shoes & 1.556 .250 & $1.040 .717,00$ & $515.532,75$ & 1,42 \\
3 & UD. Sempurna & 1.250 .000 & $885.054,00$ & $364.946,00$ & 1,36 \\
4 & Toko Sepatu Menink & 425.000 & $331.211,75$ & $93.788,25$ & 1,26 \\
5 & Kartika Exclussive & 477.500 & $402.932,75$ & $74.567,25$ & 1,17 \\
6 & PS. Ireng & 362.500 & $309.238,25$ & $53.261,75$ & 1,16 \\
7 & Soldate Leather & 361.250 & $234.019,25$ & $122.230,75$ & 1,53 \\
8 & Hidayah & 216.250 & $193.789,00$ & $22.461,00$ & 1,09 \\
9 & Rif'at & 387.500 & $293.662,50$ & $93.837,50$ & 1,27 \\
10 & Nesha Shoes & 258.750 & $212.472,75$ & $31.277,25$ & 1,14 \\
\hline & Jumlah & 6.482 .500 & $4.722 .745,05$ & $1.759 .755,90$ & 1,28 \\
\hline & Rata-rata & 648.250 & $472.274,50$ & $175.975,59$ & \\
\hline
\end{tabular}

Sumber: Data Primer diolah tahun 2019

$6)$.

Perhitungan nilai tambah menunjukkan curahan tenaga kerja selama satu kali proses produksi yang dihitung berdasarkan Hari Orang Kerja (HOK). HOK diperoleh dengan cara perhitungan perkalian antara jumlah jam kerja dan jumlah pekerja kemudian hasilnya dibagi dengan jumlah jam kerja dalam satu hari. Input tenaga kerja pembuatan sepatu wanita dan sepatu pria adalah masing-masing sebesar 1,29 HOK dengan upah per HOK sebesar Rp 2.684,19.

Nilai koefisien tenaga kerja pada pembuatan sepatu wanita sebesar 0,13 . Hasil koefisien tenaga kerja menunjukkan bahwa rata-rata kebutuhan input tenaga kerja untuk mengolah 1 feet bahan baku kulit samak produk sepatu wanita adalah sebesar 0,13 , sedangkan nilai koefisien tenaga kerja pada pembuatan sepatu pria sebesar 0,12 . Hasil koefisen tenaga kerja ini menunjukkan bahwa rata-rata kebutuhan input tenaga kerja untuk mengolah 1 feet bahan baku kulit box pada produk sepatu pria sebesar 0,12.

Harga input bahan baku sepatu wanita dan sepatu pria adalah Rp. 20.000 per feet, sedangkan total harga input lain adalah $\mathrm{Rp}$. 26.092,29 per feet bahan baku untuk sepatu wanita dan Rp. 15.753,66 per feet bahan baku untuk sepatu pria. Nilai produk yang dihasilkan pada sepatu wanita dan sepatu pria masing-masing sebesar Rp. 72.750,00 dan Rp. 51.833,31. Nilai output dikurangi dengan total harga input bahan baku dan total harga input lain sehingga menghasilkan nilai sebesar Rp. 30.707,71 untuk sepatu wanita dan Rp. 30.129,68 untuk sepatu pria. Rasio nilai tambah yang dihasilkan per feet bahan baku sepatu wanita dan laki-laki masingmasing sebesar $41,15 \%$ dan $46,62 \%$ dari harga produk sepatu wanita dan pria.

Pendapatan tenaga kerja langsung sebesar Rp. 369,65 dan Rp. 270,91 dengan rasio tenga kerja sebesar $1,39 \%$ dan $1,03 \%$. Pendapatan yang diperoleh dari produk sepatu wanita dan sepatu pria adalah sebesar Rp. 30.338,06,39 dan Rp. 29.858,77 atau sebesar $40,61 \%$ dan $46,16 \%$ dari nilai output yang dihasilkan.

Setiap pengolahan satu feet bahan baku kulit samak akan menghasilkan 0,67 pasang sandal wanita dan 0,57 pasang sandal pria. Rata-rata harga sandal wanita Rp. 102.000 dan sandal pria Rp. 115.500 per pasang. Biaya yang digunakan dalam pembuatan kulit samak adalah biaya bahan baku dan biaya 
Tabel 6. Rata-rata nilai tambah produk sepatu pria dan sepatu wanita

\begin{tabular}{|c|c|c|c|c|}
\hline No & Analisis Nilai Tambah & Formula & Sepatu Wanita & Sepatu Pria \\
\hline 1. & Output (Pasang/Produksi) & (a) & 6,80 & 4,40 \\
\hline 2. & Input Bahan Baku (Feet/Produksi) & (b) & 13,60 & 13,10 \\
\hline 3. & Input Tenaga Kerja (HOK/Produksi) & (c) & 1,29 & 1,08 \\
\hline 4. & Faktor Konversi & $(d)=(a) /(b)$ & 0,50 & 0,34 \\
\hline 5. & Koefisien Tenaga Kerja & $(e)=(c) /(b)$ & 0,13 & 0,12 \\
\hline 6. & Harga Produk (Rp/Pasang) & (f) & $145.500,00$ & $180.500,00$ \\
\hline \multirow[t]{2}{*}{7.} & Upah Tenaga Kerja (Rp/HOK) & (g) & $2.684,19$ & $2.207,84$ \\
\hline & \multicolumn{4}{|l|}{ Penerimaan dan Keuntungan (Rp/Feet) } \\
\hline 8. & Harga Bahan Baku (Rp/Feet) & (h) & $15.950,00$ & $15.950,00$ \\
\hline 9 & Harga Input Lain (Rp/Feet) & (i) & $26.092,29$ & $15.753,66$ \\
\hline 10. & Nilai Produk (Rp/Pasang) & $(j)=(d) x(f)$ & $72.750,00$ & $61.833,33$ \\
\hline \multirow[t]{2}{*}{11.} & a. Nilai Tambah (Rp/feet) & $(k)=(j)-(h)-(i)$ & $30.707,71$ & $30.129,68$ \\
\hline & b. Rasio Nilai Tambah (\%) & $(1)=(\mathrm{k} / \mathrm{j}) \times 100$ & 41,15 & 46,62 \\
\hline \multirow[t]{2}{*}{12} & a. Pendapatan Tenaga Kerja (Rp/feet) & $(\mathrm{m})=(\mathrm{e}) \mathrm{x}(\mathrm{k})$ & 369,65 & 270,91 \\
\hline & b. Rasio Tenaga Kerja (\%) & $(\mathrm{n})=(\mathrm{m} / \mathrm{k}) \times 100$ & 1,39 & 1,03 \\
\hline \multirow[t]{2}{*}{13} & a. Keuntungan (Rp/feet) & $(\mathrm{o})=(\mathrm{k})-(\mathrm{m})$ & $30.338,06$ & $29.858,77$ \\
\hline & b. Rasio Keuntungan (\%) & $(p)=(o) /(j) \times 100$ & 40,61 & 46,16 \\
\hline
\end{tabular}

Sumber: Data Primer diolah tahun 2019

bahan input lain. Harga satu feet bahan baku kulit box Rp. 15.950,- sedangkan harga input lain untuk mengolah 1 feet bahan baku kulit samak produk sandal wanita adalah sebanyak Rp. 28.574,39 dan sandal pria sebanyak Rp. 24.768,02 (Tabel 7).

Input tenaga kerja pembuatan sandal wanita dan sandal pria adalah masingmasing sebesar 1,62 HOK dengan upah per HOK sebesar Rp 3.536,25. Nilai koefisien tenaga kerja pada pembuatan sandal wanita sebesar 0,34. Hasil koefisien tenaga kerja menunjukkan bahwa rata-rata kebutuhan input tenaga kerja untuk mengolah 1 feet bahan baku kulit samak produk sandal wanita adalah sebesar 0,34 , sedangkan nilai koefisien tenaga kerja pada pembuatan sandal pria sebesar 0,58.

Pendapatan tenaga kerja langsung sebesar Rp. 1.251,03 dan Rp. 1.895,42 dengan rasio tenga kerja sebesar 5,39\% dan 7,62\%. Pendapatan yang diperoleh dari produk sandal wanita dan sandal pria adalah sebesar Rp.
$22.224,58$ dan Rp. 23.386,56 atau sebesar $31,69 \%$ dan $34,85 \%$ dari nilai output yang dihasilkan.

Harga input bahan baku sandal wanita dan sandal pria adalah Rp. 15.950 per feet, sedangkan total harga input lain adalah $\mathrm{Rp}$. 28.574,61 per feet bahan baku untuk sepatu wanita dan Rp. 15.950,00 per feet bahan baku untuk sandal pria. Nilai produk yang dihasilkan pada sandal wanita dan sandal pria masing-masing sebesar Rp. 68.000,00 dan Rp. 66.000,00. Nilai output dikurangi dengan total harga input bahan baku dan total harga input lain sehingga menghasilkan nilai sebesar Rp. 23.475,61 untuk sandal wanita dan Rp. 25.281,98 untuk sandal pria. Rasio nilai tambah yang dihasilkan per feet bahan baku sandal wanita dan pria masing-masing sebesar 33,53\% dan 37,76\% dari harga produk sandal wanita dan pria.

Nilai tambah produk sandal wanita dan pria dapat dianalisis dengan mengurangkan nilai output yang dihasilkan dengan biaya- 
Tabel 7. Rata-rata nilai tambah produk sandal pria dan sandal wanita

\begin{tabular}{|c|c|c|c|c|}
\hline No & Analisis Nilai Tambah & Formula & Sandal Wanita & Sandal Pria \\
\hline 1. & Output (Pasang/Produksi) & (a) & 4,50 & 1,90 \\
\hline 2. & Input Bahan Baku (Feet/Produksi) & (b) & 6,75 & 3,33 \\
\hline 3. & Input Tenaga Kerja (HOK/Produksi) & (c) & 1,62 & 1,38 \\
\hline 4. & Faktor Konversi & $(d)=(a) /(b)$ & 0,67 & 0,57 \\
\hline 5. & Koefisien Tenaga Kerja & $(e)=(c) /(b)$ & 0,34 & 0,58 \\
\hline 6. & Harga Produk (Rp/Pasang) & (f) & $102.000,00$ & $115.500,00$ \\
\hline \multirow[t]{2}{*}{7.} & Upah Tenaga Kerja (Rp/HOK) & (g) & $3.536,25$ & $3.176,03$ \\
\hline & Penerimaan dan Keuntungan $(\mathrm{Rp} / \mathrm{Fe}$ & & & \\
\hline 8. & Harga Bahan Baku (Rp/Feet) & (h) & $15.950,00$ & $15.950,00$ \\
\hline 9 & Harga Input Lain (Rp/Feet) & (i) & $28.574,39$ & $24.768,02$ \\
\hline 10. & Nilai Produk (Rp/Pasang) & $(j)=(d) x(f)$ & $68.000,00$ & $66.000,00$ \\
\hline \multirow[t]{2}{*}{11.} & a. Nilai Tambah (Rp/Feet) & $(k)=(j)-(h)-(i)$ & $23.475,61$ & $25.281,98$ \\
\hline & b. Rasio Nilai Tambah (\%) & $(1)=(k / j) \times 100$ & 33,53 & 37,76 \\
\hline \multirow[t]{2}{*}{12} & a. Pendapatan Tenaga Kerja (Rp/Feet) & $(\mathrm{m})=(\mathrm{e}) \mathrm{x}(\mathrm{k})$ & $1.251,03$ & $1.895,42$ \\
\hline & b. Rasio Tenaga Kerja (\%) & $(\mathrm{n})=(\mathrm{m} / \mathrm{k}) \mathrm{x} 100$ & 5,39 & 7,62 \\
\hline \multirow[t]{2}{*}{13} & a. Keuntungan (Rp/Feet) & $(\mathrm{o})=(\mathrm{k})-(\mathrm{m})$ & $22.224,58$ & $23.386,56$ \\
\hline & b. Rasio Keuntungan (\%) & $(p)=(o) /(j) \times 100$ & 31,69 & 34,85 \\
\hline
\end{tabular}

Sumber: Data Primer diolah tahun 2019

biaya yang digunakan dalam proses produksi sepatu. Produk sandal wanita memperoleh nilai tambah sebesar Rp. 23.475,61 per feet bahan baku atau $33,53 \%$ dari nilai output, sedangkan pada produk sepatu pria memperoleh nilai tambah sebesar Rp. 25.281,98 per feet bahan baku atau $37,76 \%$ dari nilai output. Hal ini juga sesuai dengan penelitian yang dilakukan oleh Kusmiyati (1999) bahwa kulit box atau kulit samak yang diolah menjadi sepatu akan memberikan nilai tambah. Perbedaan nilai tambah yang dihasilkan disebabkan oleh beberapa faktor, seperti faktor konversi, koefisien tenaga kerja, dan rasio tenaga kerja.

\section{Strategi Pengembangan}

Strategi pengembangan salah satu cara yang ditujukan untuk mengetahui langkah yang sebaiknya dilakukan untuk pengembangan industri kerajinan alas kaki dari kulit di sentra Kabupaten Magetan. Analisis yang digunakan untuk membantu perumusan strategi pengembangan industri kerajinan alas kaki dari kulit ini menggunakan
Analysis Hierarcy Process (AHP). Prinsip kerja AHP adalah menyederhanakan suatu masalah kompleks yang tidak terstruktur dan strategic dan dinamik menjadi bagian-bagian, serta menata dalam suatu hirarki (Sumiyati et al., 2011).

Kriteria yang digunakan dalam penelitian yaitu: produksi, pemasaran, sumber daya manusia (SDM) dan teknologi. Setiap kriteria ini memiliki beberapa alternatifalternatif strategi. Alternatif strategi pengembangan yang dimasukkan kedalam susunan hirarki diharapkan dapat memberi pertimbangan subyektif tentang relatif pentingnya alternatif dan mensistesis berbagai pertimbangan untuk menetapkan variabel yang memiliki nilai prioritas yang tinggi.

Ada 4 alternatif strategi yang memiliki skala prioritas tertinggi dari 10 alternatif strategi yang ada (Gambar2). Alternatif strategi tersebut adalah Pelatihan untuk meningkatkan ketrampilan teknis (A5) dengan bobot 0,189, mempertahankan kualitas produk (A2) 


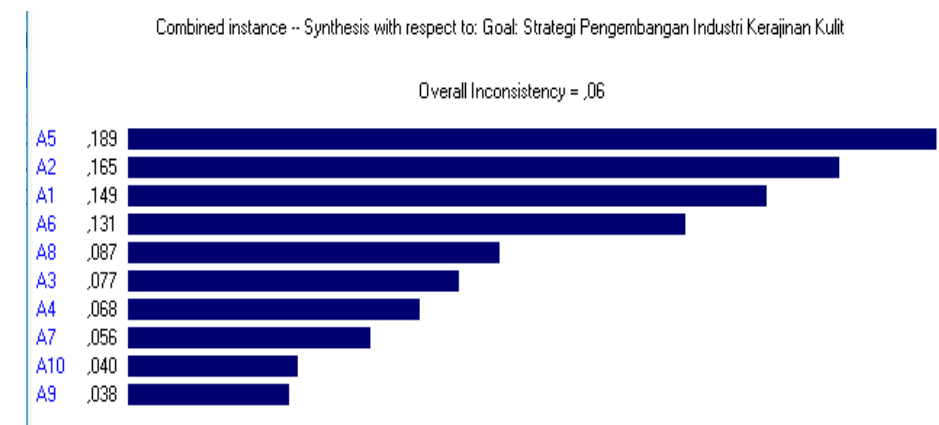

Gambar 2. Prioritas alternatif strategi pengembangan industri kerajinan alas kaki dari kulit skala kecil dan mikro di Kelurahan Selosari Kecamatan Magetan Kabupaten Magetan
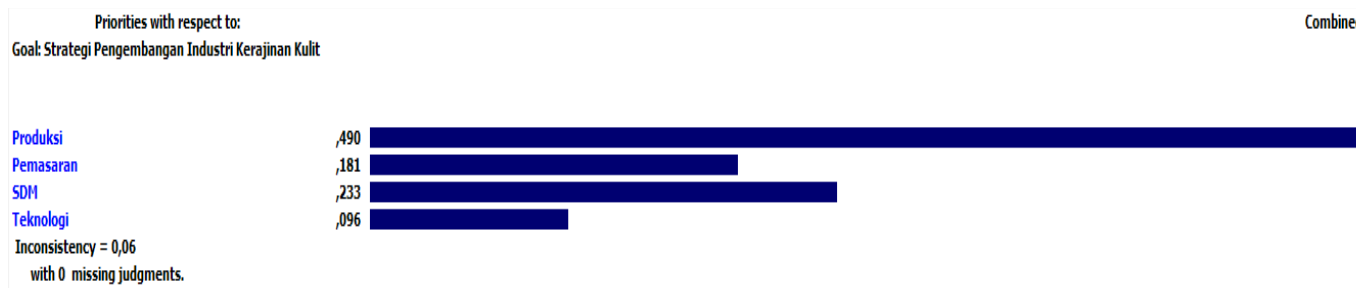

Gambar 3. Aspek strategi indutri kerajinan alas Kaki Kabupaten Magetan

dengan bobot 0,165 , melakukan pelatihan manajemen dan inovasi produk (A1) dengan bobot 0,149 , mengadakan balai latihan kerja khusus kerajinan kulit (A6) dengan bobot 0,131 . Nilai inconsistency ratio 0,06 atau lebih kecil dari 0,1 (batas maksimum) dimana artinya hasil analisis tersebut dapat diterima.

Secara umum prioritas pertama strategi pengembangan industri kerajinan alas kaki dari kulit di Kabupaten Magetan adalah strategi pelatihan untuk meningkatkan ketrampilan teknis (A5) dengan bobot 0,189; kemudian strategi mempertahankan kualitas produk (A2) dengan bobot 0,165 ; melakukan pelatihan manajemen dan inovasi produk (A1) dengan bobot 0,149 ; strategi mengadakan balai laatihan kerja khusus kerajinan kulit (A6) dengan bobot 0,131 ; strategi memberikan bantuan teknologi dengan harga terjangkau (A8) dengan bobot 0,087; memanfaatkan promosi pemerintah daerah (A3) dengan bobot 0,077 ; strategi penyediaan informasi pasar atau katalog (A4) dengan bobot 0,068 ; strategi meningkatkan pengetahuan pengolahan limbah (A7) dengan bobot 0,056; pengembangan industri mesin pengolah kulit (A10) dengan bobot 0,040; dan yang terakhir strategi pengembangan industri pengolahan limbah (A9) dengan bobot 0,038.

Prioritas kriteria dalam strategi pengembangan industri kerajinan alas kaki dari kulit di Kabupaten Magetan adalah aspek produksi dengan bobot 0,490. Kriteria selanjutnya adalah aspek SDM atau sumber daya manusia dengan bobot 0,233 ; kemudian kriteria pemasaran dengan bobot 0,181 ; dan aspek terendah yaitu teknologi dengan bobot 0,096 (Gambar 3). Hal tersebut menunjukkan bahwa pengembangan kriteria produksi memiliki dampak yang paling luas dan merupakan kriteria dasar dalam pengembangan industri kerajinan alas kaki dari kulit di Kabupaten Magetan.

\section{KESIMPULAN}

1. Rata-rata pendapatan industri kerajinan alas kaki dari kulit di sentra kerajinan kulit Kabupaten Magetan adalah sebesar Rp. 175.975,58 dengan industri Figha Shoes yang memiliki pendapatan tertinggi dan Nesha Shoes memiliki pendapatan terendah. 
2. Efisiensi penggunaan biaya produksi pada industri kerajinan di sentra kerajinan Kabupaten Magetan adalah sebesar 1,23, yang artinya setiap penggunaan biaya sebesar 1 rupiah maka akan mendapatkan penerimaan sebesar Rp. 1,23 dan keuntungan sebesar 0,23 rupiah. Efisiensi penggunaan biaya produksi tertinggi adalah industri Soldate Leather dan yang terendah adalah HIDAYAH.

3. Produk kerajinan alas kaki dari kulit Kabupaten Magetan memberikan nilai tambah. Nilai tambah tertinggi pada produk sepatu wanita dengan nilai tambah sebesar Rp. 30.707,71 per feet bahan baku dimana artinya adalah nilai tambah dari produk sepatu wanita setiap satu feet bahan baku adalah sebesar Rp. 30.707,71. Nilai tambah kedua adalah produk sepatu laki-laki dengan nilai tambah sebesar Rp. 30.129,60 per feet bahan baku. Nilai tambah ketiga adalah produk sandal laki-laki dengan nilai tambah sebesar Rp. 25.281,98, sedangkan nilai tambah terendah adalah produk sandal wanita dengan nilai tambah sebesar $\mathrm{Rp}$. 23.475,61.

4. Strategi pengembangan yang dipandang relative tepat untuk industri kerajinan kulit Kabupaten Magetan di Kabupaten Magetan adalah kriteria produksi dengan bobot 0,490, kemudian dilanjutkan dengan kriteria SDM $(0,233)$, kriteria pemasaran $(0,181)$ dan teknologi $(0,096)$, sedangkan alternative yang perlu diperhatikan adalah melakukan pelatihan ketrampilan teknis dimana bobotnya yaitu 0,189 .

\section{SARAN}

1. Apabila industri kerajinan alas kaki dari kulit Kabupaten Magetan menginginkan pendapatan, efisiensi penggunaan biaya dan nilai tambah yang cenderung tinggi maka sebaiknya menambah produksi pada produk sepatu pria, sedangkan untuk produk lain agar bisa memiliki pendapatan, nilai efisiensi penggunaan biaya dan nilai tambah yang lebih tinggi sebaiknya menekan pada biaya produksi atau meningkatkan harga dari produk.

2. Industri kerajinan alas kaki dari kulit Kabupaten Magetan sebaiknya melakukan pelatihan ketrampilan teknis dalam proses upper atau pembuatan kap, assembling dan finishing untuk SDM-nya sehingga dapat meningkatkan kinerja dan kualitas produk, karena prioritas kriteria yang dipandang relative tepat yaitu kriteria produksi.

\section{DAFTAR PUSTAKA}

Badan Pusat Statustik. 2016. Kabupaten Magetan dalam Angka 2015. Magetan: Badan Pusat Statistik

Badan Pusat Statustik. 2017. Kabupaten Magetan dalam Angka 2016. Magetan: Badan Pusat Statistik.

Badan Pusat Statustik. 2018. Kabupaten Magetan dalam Angka 2017. Magetan: Badan Pusat Statistik.

Darojat, N. I. 2014. Pengembangan Industri Tanduk Desa Pucang Kecamatan Secang Skala Mikro Kecil, Kabupaten Magelang. Jejak, 7(1): 29-45.

Erawati, R. V. dan Kirwani. 2014. Kontribusi Industri Kerajinan Kulit Bagi Pendapatan Tenaga Kerja di Kabupaten Magetan. JUPE, 2(3): 1-13.

Hadinata, R. 2014. Analisis Strategi Pengerajin Kulit dalam Mngembangkan Usaha (Studi Kasus di Sentra Industri Kerajinan Kulit Kelurahan Selosari Magetan). JSEP, 6(2):173-182.

Hariyati, Y. 2007. Ekonomi Mikro(Pendekatan Matematis dan Grafis). Jember: CSS.

Kusmiyati, Y. 1999. Analisis Nilai Tambah Produksi dan Peranan Pemerintah Terhadap Pengembangan Industri Kecil Sepatu (Joan's Shoes dan PD. Karya Dian Shoes Cibaduyut, Bandung). Skripsi. Bogor: Jurusan Ilmu-Ilmu 
Sosial Ekonomi Pertanian, Fakultas Pertanian, Institut Pertanian Bogor.

Marimin dan Maghfiroh, N. 2010. Aplikasi Teknik Pengambilan Keputusan dalam Manajemen Rantai Pasok. Bogor: Unit Penerbit dan Percetakan IPB.

Mulyono, S. 1996. Teori Pengambilan Keputusan. Jakarta: Fakultas Ekonomi Universitas Indonesia Jakarta.

Saaty, T. L. 1991. Pengambilan KeputusanBagi Para Pemimpin. Jakarta: PT. Dharma Aksara Perkasa.

Setyaningsih, D. W. 2017. Nilai Ekonomis Kulit Sapi Sebagai Bahan Baku Pembuatan Alas Kaki. Media Soerjo, 20(1): 74-84.

Soekartawi. 1995. Analisis Usaha Tani. Jakarta: Rajawali Pers.
Soetriono., Marta, F., Hidayat, A. dan Ratna, D. 2017. Daya Saing Agribisnis Kopi Robusta Sebuah Prespektif Ekonomi. Malang: Intimedia.

Sumiyati., Sutiarso, L., Windia, I. W., dan Sudira, P. 2011. Aplikasi Analytical Hierarchy Process (AHP) untuk penentuan Strategi Pengembangan Subak. Agritech,31(2):138-145.

Waluyo. 2008. Akuntansi Pajak. Jakarta: Penerbit Salemba Empat.

Wibowo, A. 2009. Analisis Kinerja dan Strategi Pengembangan Usaha Kerajinan Sepatu di Kabupaten Bogor (Studi Kasus Pada Cv. Anugerah Jaya, Desa Suka Makmur, Kecamatan Ciomas). Skripsi. Bogor: Departemen Ilmu Ekonomi Fakultas Ekonomi dan Manajemen Institut Pertanian Bogor. 